\title{
Drying of semicrystalline polymers: mathematical modeling and experimental characterization of poly(vinyl alcohol) films
}

\author{
Sim-Siong Wong ${ }^{\mathrm{a}}$, Sacide Alsoy Altınkaya ${ }^{\mathrm{b}}$, Surya K. Mallapragada ${ }^{\mathrm{a}, *}$ \\ ${ }^{a}$ Department of Chemical Engineering, Iowa State University, 2114, Sweeney Hall, Ames, IA 50011-2230 USA \\ ${ }^{\mathrm{b}}$ Department of Chemical Engineering, Izmir Institute of Technology, Gulbahce Koyu, 35437 Urla-Izmir, Turkey
}

Received 24 February 2004; received in revised form 11 May 2004; accepted 13 May 2004

Available online 5 June 2004

\begin{abstract}
A mathematical model was developed to predict the drying mechanism of semicrystalline polymers involving multiple solvents. Since drying of semicrystalline polymers can be accompanied by changes in polymer degree of crystallinity, the model integrates crystallization kinetics and the Vrentas-Duda diffusion model to provide a better understanding of the mechanism. The model considers the effect of external conditions such as temperature, film shrinkage and diffusion and evaporation of multiple solvents during drying. Poly(vinyl alcohol) (PVA)/water/methanol was chosen as a test system. The drying kinetics of PVA films swollen in water and methanol were investigated using gravimetric techniques. The model predicts that higher temperatures, lower film thicknesses and lower methanol to water ratios increase the drying rate. The model predictions were compared with experimental data and showed good agreement.

(C) 2004 Elsevier Ltd. All rights reserved.
\end{abstract}

Keywords: Drying; Semicrystalline polymers; Poly(vinyl alcohol)

\section{Introduction}

Drying of polymeric films is a crucial process for manufacturing various commercial products, including adhesive tapes, photographic films, functional coatings and magnetic media [1,2]. During drying, properties of the polymer, including its microstructure, change considerably. Besides, the amount of residual solvent left in the final product is an important factor in the polymer drying process, since these solvents can be harmful [3-5]. Thus, the fundamentals of solvent evaporation from polymers are crucial. The behavior of amorphous polymers during drying has been well studied [1,2,6-22]. However, the behavior of semicrystalline polymers under different drying conditions, and changes in polymer microstructure during removal of multiple solvents, has received little attention.

This work focuses on the development of a mathematical model for semicrystalline polymer drying involving removal of multiple solvents. With semicrystalline polymers, the crystallinity of the polymer can change as drying occurs, which in turn, affects the drying rate as crystals in

\footnotetext{
* Corresponding author. Tel.: + 1-515-294-7407; fax: + 1-515-294-2689.

E-mail address: suryakm@iastate.edu (S.K. Mallapragada).
}

the polymer hinder the diffusion of solvents [23-25]. A complex diffusion scheme that includes interaction between the polymer and each solvent and between the solvents themselves is needed. Furthermore, the polymer crystallization kinetics during removal of the two solvents needs to be accounted for. These behaviors add layers of complexity in understanding how drying occurs. Along with the model development, experimental procedures have been designed to investigate the drying behavior and compare with the simulation results.

\section{Mathematical modeling}

Several mathematical models for describing the drying behavior of amorphous polymers have been proposed by various researchers [1,2,19-22], but there have been few studies of multicomponent semicrystalline polymer drying $[24,25]$. A schematic setup of the drying process is shown in Fig. 1. Initially the polymer film has a thickness of $L_{0}$, and is placed on an impermeable substrate of constant thickness $H$. The polymer and substrate are exposed to hot air on both sides. As the drying occurs, the solvent evaporates out of the polymer causing the film thickness as well as solvent 


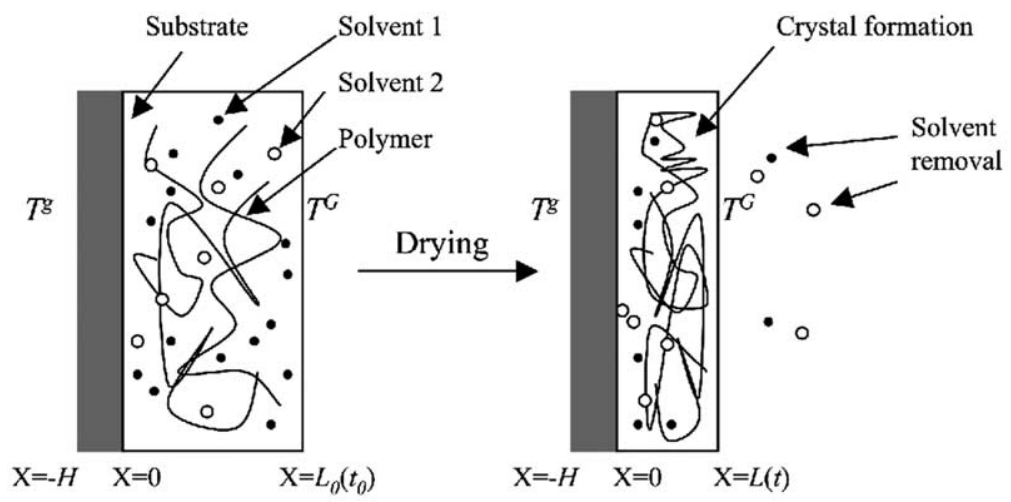

Fig. 1. The drying mechanism of semicrystalline polymer/solvent/solvent system involving solvent removal, film shrinkage and crystallization.

concentration inside the film change accordingly. At the same time, polymer undergoes solvent-induced crystallization.

One dimensional transport is assumed for its simplicity, since the thickness of the polymer film is much smaller than the other dimensions of the film. Assuming that there is no volume change of mixing, volume fractions are used in the formulation of mass transfer equations. The polymer system is composed of four components represented by $N$; solvent 1 , solvent 2, amorphous polymer and crystalline polymer, and are numbered accordingly. The volume fractions of solvent 1 and solvent 2 are labeled as $w_{1}$ and $w_{2}$ respectively, volume fraction of amorphous polymer is labeled as $u$ and volume fraction of crystalline polymer is labeled as $v$.

The equations that govern the solvent removal are as follows:

$\frac{\partial w_{i}}{\partial t}=\frac{\partial}{\partial x}\left(\sum_{j=1}^{N-2} D_{i j} \frac{\hat{V}_{i}}{\hat{V}_{j}} \frac{\partial w_{j}}{\partial x}\right)$

where $w_{i}$ is the volume fraction of component $i, \hat{V}_{i}$ and $\hat{V}_{j}$ represent the partial specific volume of the component $i$ and $j$, and $D_{i j}$ represent the multicomponent diffusion coefficients [1]. In deriving this equation, the polymer is assumed to be non-reactive and the mass transfer is assumed to take place only because of diffusion of $N-2$ solvents as shown in Eq. (1).

For two solvent systems, a series of four diffusion coefficients are written to describe the diffusion and thermodynamic interactions of each component, as developed by Alsoy and Duda [1]. In Eqs. (2)-(5), $D_{i}$ and $\mu_{i}$ represent self diffusion coefficient and chemical potentials of component $i$, respectively.

$$
\begin{aligned}
& D_{11}=D_{1} \frac{w_{1}}{\hat{V}_{1}}\left(1-w_{1}\right) \frac{1}{R T} \frac{\partial \mu_{1}}{\partial \rho_{1}}-D_{2} \frac{w_{1}}{\hat{V}_{1}} w_{2} \frac{1}{R T} \frac{\partial \mu_{2}}{\partial \rho_{1}} \\
& D_{12}=D_{1} \frac{w_{1}}{\hat{V}_{1}}\left(1-w_{1}\right) \frac{1}{R T} \frac{\partial \mu_{1}}{\partial \rho_{2}}-D_{2} \frac{w_{1}}{\hat{V}_{1}} w_{2} \frac{1}{R T} \frac{\partial \mu_{2}}{\partial \rho_{2}} \\
& D_{21}=D_{2} \frac{w_{2}}{\hat{V}_{2}}\left(1-w_{2}\right) \frac{1}{R T} \frac{\partial \mu_{2}}{\partial \rho_{1}}-D_{1} \frac{w_{2}}{\hat{V}_{2}} w_{1} \frac{1}{R T} \frac{\partial \mu_{1}}{\partial \rho_{1}}
\end{aligned}
$$

$$
D_{22}=D_{2} \frac{w_{2}}{\hat{V}_{2}}\left(1-w_{2}\right) \frac{1}{R T} \frac{\partial \mu_{2}}{\partial \rho_{2}}-D_{1} \frac{w_{2}}{\hat{V}_{2}} w_{1} \frac{1}{R T} \frac{\partial \mu_{1}}{\partial \rho_{2}}
$$

Self diffusion coefficients in these equations are obtained from Vrentas-Duda free volume theory [26-29] as shown in Eqs. (6) and (7).

$$
\begin{aligned}
D_{1}= & \frac{D_{\mathrm{o} 1}}{\tau} \exp \left[-\frac{E_{1}}{R T}\right] \\
& \exp \left[-\frac{\omega_{1} \hat{V}_{1}^{*}+\omega_{2} \hat{V}_{2}^{*} \frac{\xi_{13}}{\xi_{23}}+\omega_{3} \hat{V}_{3}^{*} \xi_{13}}{\frac{\hat{V}_{\mathrm{FH}}}{\gamma}}\right] \\
D_{2}= & \frac{D_{\mathrm{o} 2}}{\tau} \exp \left[-\frac{E_{2}}{R T}\right] \\
& \exp \left[-\frac{\omega_{1} \hat{V}_{1}^{*} \frac{\xi_{23}}{\xi_{13}}+\omega_{2} \hat{V}_{2}^{*}+\omega_{3} \hat{V}_{3}^{*} \xi_{23}}{\frac{\hat{V}_{\mathrm{FH}}}{\gamma}}\right]
\end{aligned}
$$

Here, $D_{\mathrm{o} i}$ is the pre-exponential factor, $\tau$ is the tortuosity, $E_{i}$ is the activation energy for jumping unit to be free, $\omega_{i}$ is the mass fraction of component $i, \hat{V}_{i}^{*}$ is the specific critical hole free volume of component $i$ required for a jump to occur and $\xi_{i j}$ is the ratio between the critical molar volume of the solvent jumping unit and the critical molar volume of the polymer jumping unit. The average hole free volume per gram of mixture, $\hat{V}_{\mathrm{FH}} / \gamma$ is shown in Eq. (8).

$$
\begin{aligned}
\frac{\hat{V}_{\mathrm{FH}}}{\gamma}= & \omega_{1} \frac{K_{11}}{\gamma}\left(K_{21}-T_{\mathrm{g} 1}+T\right)+\omega_{2} \frac{K_{12}}{\gamma}\left(K_{22}-T_{\mathrm{g} 2}\right. \\
& +T)+\omega_{3} \frac{K_{13}}{\gamma}\left(K_{23}-T_{\mathrm{g} 3}+T\right)
\end{aligned}
$$

In Eq. (8), $K_{1 i}$ and $K_{2 i}$ are free volume parameters and $T_{\mathrm{g} i}$ is the glass transition temperature of component $i$. While the relationships given by Eqs. (6)-(8) contain several parameters, each one of them has a physical meaning and most of them can be estimated a priori without the use of any diffusivity data. Zielinki and Duda [30] developed 
procedures for calculating these parameters. Usually, $D_{\mathrm{o} i}, E_{i}$ and $\xi_{i j}$ are determined from a non-linear regression fit of the self diffusion data to Eqs. (6) and (7). We have modified the self-diffusion equation developed by Vrentas and Duda with the addition of a tortuosity term. The tortuosity term arises from the fact that crystals in the polymer hinder the diffusion of the solvent through the polymer. In semicrystalline polymers, solvent must follow tortuous paths through the amorphous portion of the polymer to get around the crystals in the polymer. Harland and Peppas [31] have shown that the value of $\tau$ is equal to 3.0 for diffusion of small molecules through semicrystalline polymer, unless the volume fraction of crystals is very small. In our work, we assume that $\tau$ is equal to 3.0 when $v$ is greater than 0.05 , otherwise, the effect of tortuosity can be neglected, and $\tau$ is equal to 1.0 .

Chemical potentials are used in determining the thermodynamic factors in diffusion and partial pressure of solvents at the interface, and can be calculated using ternary Flory-Huggins theory [32] and shown in Eqs. (9) and (10), where $\chi_{i j}$ is the interaction parameter between two components.

$$
\begin{aligned}
\frac{\mu_{1}-\mu_{1}^{0}}{R T}= & \ln w_{1}+\left(1-w_{1}\right)-w_{2} \\
& +\left(\chi_{12} w_{2}+\chi_{13} u\right)\left(1-w_{1}\right)-\chi_{23} w_{2} u \\
\frac{\mu_{2}-\mu_{2}^{0}}{R T}= & \ln w_{2}+\left(1-w_{2}\right)-w_{1}+\left(\chi_{12} w_{1}+\chi_{23} u\right) \\
& \times\left(1-w_{2}\right)-\chi_{23} w_{1} u
\end{aligned}
$$

At the polymer-substrate boundary, there is assumed to be no mass transfer. Hence

$$
\frac{\partial w_{i}}{\partial x}=0
$$

and at the polymer-gas boundary, mass balances are written based on the jump mass balance incorporating the mass transfer rate, the shrinking film effect and the diffusion rate of solvent [1].

$-\frac{D_{i 1}}{\hat{V}_{1}} \frac{\partial w_{1}}{\partial x}-\frac{D_{i 2}}{\hat{V}_{2}} \frac{\partial w_{2}}{\partial x}-\frac{w_{i}}{\hat{V}_{i}} \frac{\mathrm{d} L}{\mathrm{~d} t}=k_{i}^{\mathrm{G}}\left(P_{i i}^{\mathrm{G}}-P_{i \mathrm{~b}}^{\mathrm{G}}\right)$

Here $\mathrm{d} L / \mathrm{d} t$ is the change of film thickness, $k_{i}^{\mathrm{G}}$ the mass transfer coefficient of solvent $i, P_{i i}^{\mathrm{G}}$ is the partial pressure of solvent $i$ at the polymer-gas interface, and $P_{i \mathrm{~b}}^{\mathrm{G}}$ is the bulk partial pressure of solvent $i$. As mentioned before, the change in film thickness is governed by the rate of solvent removal:

$$
\frac{\mathrm{d} L}{\mathrm{~d} t}=\sum_{i=1}^{N-2} k_{i}^{\mathrm{G}} \hat{V}_{i}\left(P_{i i}^{\mathrm{G}}-P_{i \mathrm{~b}}^{\mathrm{G}}\right)
$$

As the drying continues, the polymer starts to align itself to form crystals, leading to an increase in the degree of crystallinity. Ngui and Mallapragada [24,25] used a first- order kinetic expression to predict the crystallinity growth for a single solvent system, and this expression is extended to multiple solvent systems as shown in Eq. (14).

$$
\frac{\partial v}{\partial t}=\sum_{i=1}^{N-2} k_{i} w_{i}
$$

Here, we assume that the crystallization process follows first order kinetics. The assumption of volume fraction proportionality is at its simplest form. The folding rate, $k_{i}$, proposed by Lauritzen and Hoffman [33], can be calculated for the polymer in the presence of each solvent.

$$
\begin{aligned}
k_{\mathrm{i}}= & 2 \frac{k T}{h} N_{0} \exp \left[\frac{l\left(b \sigma_{\mathrm{s}}-b w \Delta G\right)}{k T}\right] \\
& \times \exp \left[\frac{2 b w \sigma_{\mathrm{e}}}{k T}\right] \sin h\left[\frac{b w\left(l \Delta G-2 \sigma_{\mathrm{e}}\right)}{2 k T}\right]
\end{aligned}
$$

where $\sigma_{\mathrm{e}}$ and $\sigma_{\mathrm{s}}$ is the end and side surface free energies for the crystal, $\Delta G$ is the free volume change for polymer folding, and $l, b$, and $w$ are the length, thickness and width of the crystals, respectively. Schultz [34] reported values of $\sigma_{\mathrm{e}}$ and $\sigma_{\mathrm{s}}$, and $\Delta G$ can be calculated using the heat of fusion and polymer crystal melting temperature.

For the heat transfer section of the model, we assume the polymer-substrate system is thin enough, and the convective heat transfer resistance in gas phase is much greater than the conductive heat transfer resistance inside the system, resulting in no temperature gradients. Thus an overall temperature was used. The heat transfer between the gas-polymer, gas-substrate, and energy loss due to evaporation of solvents are included in calculating the overall temperature of the polymer-substrate.

$\frac{\mathrm{d} T}{\mathrm{~d} t}=$

$$
-\left[\frac{h^{\mathrm{G}}\left(T-T^{\mathrm{G}}\right)+h^{\mathrm{g}}\left(T-T^{\mathrm{g}}\right)+\sum_{i=1}^{N-2} k_{i}^{\mathrm{G}} \Delta \hat{H}_{i}\left(P_{i i}^{\mathrm{G}}-P_{i \mathrm{~b}}^{\mathrm{G}}\right)}{\rho^{p} \hat{C}_{p}^{p} L(t)+\rho^{\mathrm{s}} \hat{C}_{p}^{\mathrm{s}} H}\right]
$$

Here $h^{\mathrm{G}}, T^{\mathrm{G}}, h^{\mathrm{g}}, T^{\mathrm{g}}$ are the heat transfer coefficients and temperature for top side and bottom side, respectively, $\Delta \hat{H}_{i}$ is the latent heat of vaporization and $\hat{C}_{p}$ is the heat capacity.

Since the film thickness changes with time, the moving boundary problem was converted to a fixed boundary problem using a Landau transform where a normalized position, $x^{*}$, is defined [35]. Then, a variable-sized grid with finer mesh near gas-polymer interface was applied. This is to ensure accurate calculation near the interface where the concentration gradient is steep. The set of equations was solved using finite element methods with MATLAB ${ }^{\circledR}$ (MathWorks, Natick, MA) and FEMLAB ${ }^{\circledR}$ (Comsol, Burlington, MA) on Intel ${ }^{\circledR}$ Pentium ${ }^{\circledR} 4$ based computer. The free volume parameters used for the simulations are 
shown in Table 1. Tables 2 and 3 list the physical properties and initial and boundary conditions used for a PVA/water/ methanol system.

\section{Experimental}

\subsection{Materials}

Poly(vinyl alcohol) (PVA) was chosen because of its semicrystalline properties and as it is widely used in industries such as coating and film making. PVA (Elvanol ${ }^{\circledR}$ grades, E. I. du Pont de Nemours, Wilmington, DE) with $\bar{M}_{\mathrm{n}}=133,000$ 48,000, 64,000 and PVA (Polysciences, Warrington, PA) with $\bar{M}_{\mathrm{n}}=133,000$ were used. All PVA samples used were fully hydrolyzed (degree of hydrolysis $>99.0 \%$ ) and the polydispersity indices were 2.15 .

\subsection{Sample preparation}

PVA film was obtained by dissolving PVA powder in water $(5 \% \mathrm{w} / \mathrm{v})$ at $90{ }^{\circ} \mathrm{C}$ for $6 \mathrm{~h}$ and casting $25 \mathrm{ml}$ of the PVA aqueous solution into $100 \times 15 \mathrm{~mm}$ siliconized Petri dishes. Films were dried at $23{ }^{\circ} \mathrm{C}$ for at least 5 days until constant film weight was achieved. The average thickness of the film produced was $0.20 \mathrm{~mm}$. Once the film was ready, it was removed from the Petri dish and cut into $3 \times 3 \mathrm{~cm}^{2}$ pieces. The crystallinity of the film created via this method is approximately $40 \%$.

\subsection{Drying kinetics}

The initial weight of the film was measured, and the film was swollen in methanol and water separately. Because of

Table 1

Free volume parameters used in mathematical modeling for PVA/water (solvent 1)/methanol (solvent 2) [38]

\begin{tabular}{lll}
\hline Parameter & PVA/water & PVA/methanol \\
\hline$D_{\mathrm{oi}}\left(\mathrm{cm}^{2} \mathrm{~s}^{-1}\right)$ & 0.941 & 0.00155 \\
$E_{i}\left(\mathrm{~J} \mathrm{~mol}^{-1}\right)$ & 7978 & -3585 \\
$K_{11} / \gamma\left(\mathrm{cm}^{3} \mathrm{~g}^{-1} \mathrm{~K}^{-1}\right.$ & 0.00165 & - \\
$K_{12} / \gamma\left(\mathrm{cm}^{3} \mathrm{~g}^{-1} \mathrm{~K}^{-1}\right)$ & - & 0.000564 \\
$K_{13} / \gamma\left(\mathrm{cm}^{3} \mathrm{~g}^{-1} \mathrm{~K}^{-1}\right)$ & 0.000229 & 0.000229 \\
$K_{21}(\mathrm{~K})$ & -141.73 & - \\
$K_{22}(\mathrm{~K})$ & - & 23.87 \\
$K_{23}(\mathrm{~K})$ & -214.87 & -214.87 \\
$T_{\mathrm{g} 1}(\mathrm{~K})$ & 0 & - \\
$T_{\mathrm{g} 2}(\mathrm{~K})$ & - & 0 \\
$T_{\mathrm{g} 3}(\mathrm{~K})$ & 0 & 0 \\
$V_{1}^{*}\left(\mathrm{~cm}^{3} \mathrm{~g}^{-1}\right)$ & 1.071 & - \\
$V_{2}^{*}\left(\mathrm{~cm}^{3} \mathrm{~g}^{-1}\right)$ & - & 0.959 \\
$V_{3}^{*}\left(\mathrm{~cm}^{3} \mathrm{~g}^{-1}\right)$ & 0.720 & 0.720 \\
$\xi_{i j}$ & 0.45 & 0.99 \\
$\chi_{i 3}$ & 0.67 & 1.26 \\
$\chi_{12}$ & 0.442 & 0.442 \\
\hline
\end{tabular}

Table 2

Properties of the polymer system

\begin{tabular}{ll}
\hline Film properties & \\
Heat capacity, $\hat{C}_{p}^{p}$ & $1.674\left(\mathrm{~J} \mathrm{~g}^{-1} \mathrm{~K}^{-1}\right)$ \\
Density of film, $\rho^{p}$ & $1.294\left(\mathrm{~g} \mathrm{~cm}^{-3}\right)$ \\
Heat of vaporization of water, $\Delta \hat{H}_{1}$ & $2404\left(\mathrm{~J} \mathrm{~g}^{-1}\right)$ \\
Heat of vaporization of methanol, $\Delta \hat{H}_{2}$ & $1155\left(\mathrm{~J} \mathrm{~g}^{-1}\right)$ \\
Crystallization kinetic coefficient, $k_{i}$ & $1 \times 10^{-5}\left(\mathrm{~s}^{-1}\right)$ \\
Substrate properties & \\
Heat capacity, $\hat{C}_{p}^{\mathrm{s}}$ & $0.84\left(\mathrm{~J} \mathrm{~g}^{-1} \mathrm{~K}^{-1}\right)$ \\
Density of substrate, $\rho^{\mathrm{s}}$ & $2.6\left(\mathrm{~g} \mathrm{~cm}^{-3}\right)$ \\
Substrate thickness, $H$ & $0.012(\mathrm{~cm})$ \\
\hline
\end{tabular}

the different absorption rates of the solvents, the time required to achieve desired initial concentration might vary. One drawback of swelling the film in solvents separately instead of swelling it in a pre-mixed water-methanol mixture is that there is a possibility that some solvent might diffuse out of the polymer, thus affecting the initial concentration of the polymer system. To avoid this potential problem, the films were swollen in methanol first because of its lower absorption rate, thus minimizing the amount of time for methanol to diffuse out of the system when the film is placed in water. Furthermore, the residual water after the film was removed was tested for methanol content using gas chromatography (SRI 8610, SRI Instruments, Torrance, CA) to ensure that there is no methanol diffusion out of the polymer. Once the desired initial concentration was achieved, the film was removed from the solvent and cut into four $1.5 \times 1.5 \mathrm{~cm}^{2}$ pieces and dried at $25^{\circ} \mathrm{C}$ in an oven. The weight of the polymer film was measured periodically until it remained constant.

\subsection{Crystallization kinetics}

The degree of crystallinity of the initial film was determined using differential scanning calorimetry (DSC)

Table 3

Initial and operating conditions for PVA/water/methanol system [39,40]

Initial conditions

Temperature, $T_{0} \quad 298(\mathrm{~K})$

Film thickness, $L_{0} \quad 0.025(\mathrm{~cm})$

Initial volume fraction of solvent $1, w_{10} \quad 0.50$

Initial volume fraction of solvent $2, w_{20} \quad 0.15$

Initial volume fraction of crystalline polymer, $v_{0} \quad 0.02$

Initial volume fraction of amorphous polymer, $u_{0} \quad 0.33$

Operating conditions

Gas-polymer heat transfer coefficient, $h^{\mathrm{G}} \quad 0.02944\left(\mathrm{~W} \mathrm{~cm}^{-2} \mathrm{~K}^{-1}\right)$ Gas-substrate heat transfer coefficient, $h^{\mathrm{g}} \quad 0.01230\left(\mathrm{~W} \mathrm{~cm}^{-2} \mathrm{~K}^{-1}\right)$ Top-side air temperature, $T^{\mathrm{G}}$

Bottom-side air temperature, $T^{\mathrm{g}}$

Solvent 1 mass transfer coefficient, $k_{i}^{\mathrm{G}}$

Solvent 2 mass transfer coefficient, $k_{i}^{g}$

Mole fraction of solvent 1 in gas

Mole fraction of solvent 2 in gas

\section{$310(\mathrm{~K})$}

$310(\mathrm{~K})$

$1.8 \times 10^{-10}\left(\mathrm{~s} \mathrm{~cm}^{-1}\right)$

$2.3 \times 10^{-13}\left(\mathrm{~s} \mathrm{~cm}^{-1}\right)$

0

0 
(DSC7, Perkin-Elmer, Boston, MA) where a small piece of PVA film was heated from 25 to $250{ }^{\circ} \mathrm{C}$ at $10{ }^{\circ} \mathrm{C} / \mathrm{min}$. The heat required to melt the crystals in the sample is compared to that of pure crystals $(138.6 \mathrm{~J} / \mathrm{g})$ to obtain the initial degree of crystallinity [36].

\section{Results and discussion}

In order for the model to predict the drying behavior of polymer films, free volume parameters for the entire system must be obtained. These parameters are essential in predicting the diffusion of solvents accurately. Table 1 shows the free volume parameters for PVA-watermethanol system. Table 2 shows the physical properties of the system. Based on Eqs. (11)-(16), the initial and operating conditions for the system needed to be determined before the simulations were performed. Figs. 2-6 show the simulation results corresponding to initial and operating conditions listed in Table 3. The external conditions are used as fitting parameters in the model. In Fig. 2, the average volume fraction of individual solvents is shown. The average volume fraction of water drops rapidly as drying progresses and most water was removed after $50 \mathrm{~min}$ while the methanol volume fraction rises to a maximum at $50 \mathrm{~min}$ before decreasing slightly. The rise of volume fraction in methanol is due to the different solvent removal rates in which water is removed much faster than methanol. As water is removed from the system, total volume of the system decreases and causes volume fraction of methanol to increase, despite the fact that the overall mass of methanol is decreasing during that period. This behavior appears similar to what has been observed before in another system [1].
Fig. 3 shows the change of film thickness as drying occurs. The film thickness decreases rapidly and levels off after $50 \mathrm{~min}$. This figure follows the trend of the overall solvent removal kinetics. Figs. 4 and 5 shows the volume fraction of water and methanol, respectively, across the polymer film at 1, 10 and 100 min of drying time. In Fig. 4, the differences in volume fraction across the polymer film are minimal, suggesting that the rate of removal of water is governed by evaporation of water from the surface. In Fig. 5, the concentration gradient of methanol increases as drying continues since the rate of drying is now controlled by diffusion of methanol in the polymer. The difference in the ease of diffusion for the two solvents is due to the size of the solvent molecules and the fact that PVA interacts better with water than with methanol. The volume fraction of crystals in the system increases with drying time as shown in Fig. 6 where the rate of crystal growth is showing a slow down near 25 min which corresponds to the time when most of the water has been removed from the system, suggest that water removal may course a greater change in degree of crystallinity of the polymer.

Several initial and operating conditions were varied to study the effect of surrounding temperature, initial film thickness, and initial methanol to water ratio in total solvent removal from the system. Three temperature settings (300, 310 and $320 \mathrm{~K}$ ) were used for studying the effect of temperature on the system, with other parameters set as per Table 3. The results are shown in Fig. 7. With increase in surrounding temperature, the initial solvent removal rate increased due to an increase in the activity of each solvent, thus increasing the driving force for the evaporation of solvents. Furthermore, at higher surrounding temperatures, a sharper change in solvent removal rate was observed until

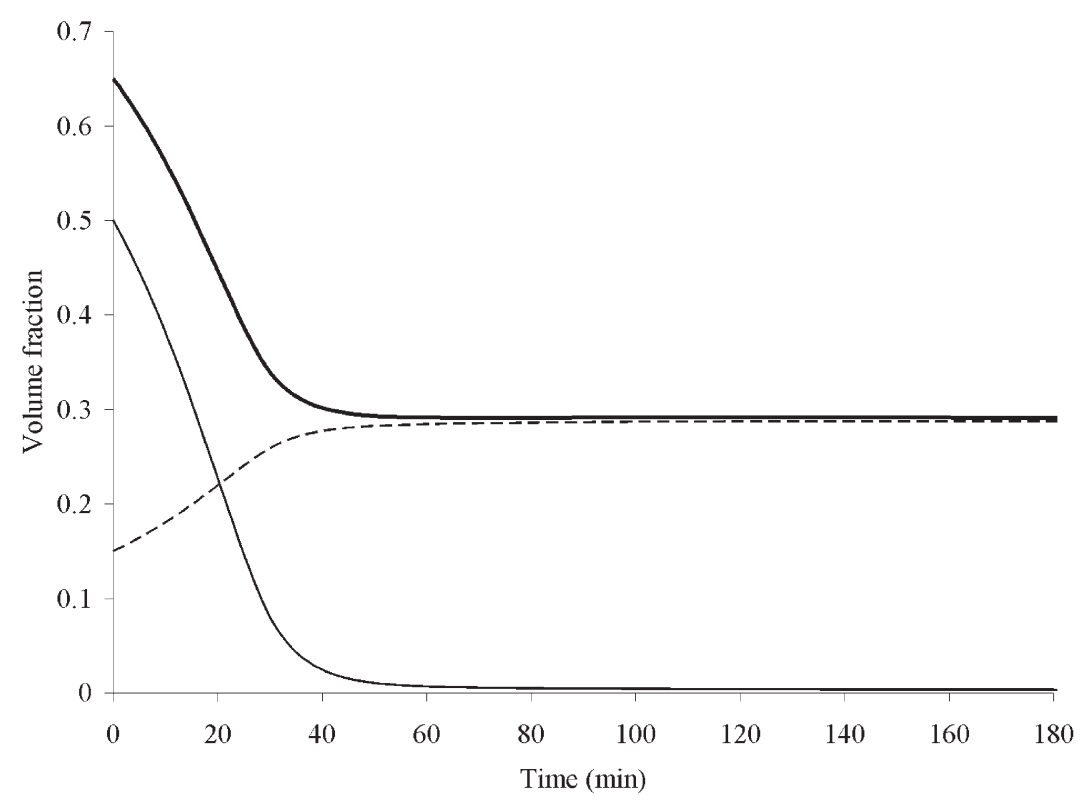

Fig. 2. Average volume fraction of the solvents during drying. (-) represents the total volume fraction of the solvents in the system, (-) represents the volume fraction of water in the system and the (- -) represents the volume fraction of methanol. 


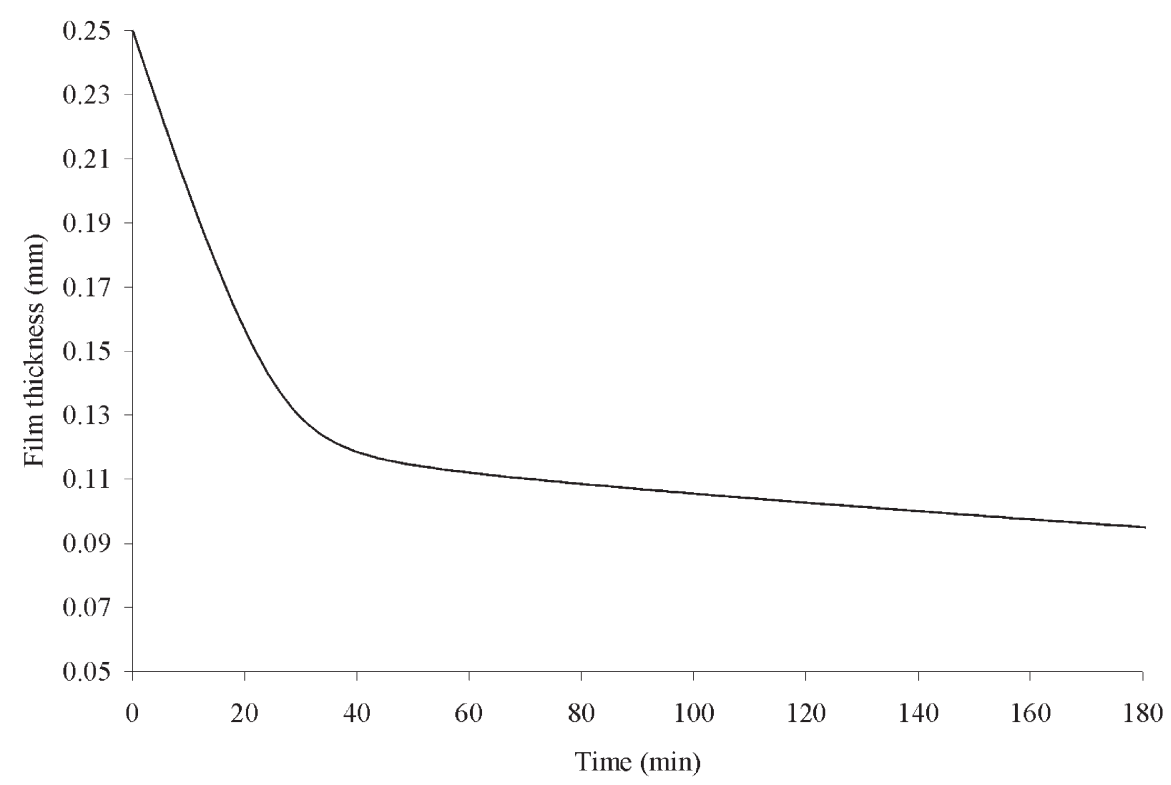

Fig. 3. The change of polymer film thickness (-) during drying.

the total solvent remaining dropped to approximately $20 \%$. At later stages of drying, especially after $100 \mathrm{~min}$, the total residual amount of solvents does not significantly change since drying within this region is controlled by strong diffusional resistance inside the polymer film. A closer examination of the simulation data at each temperature revealed that at the time when most of the water was removed, there was still considerable amount of methanol left in the system. We conclude that air temperature can be increased to reduce the drying time by increasing the initial rate of evaporation and the overall rate of solvent removal in the polymer film.

In studying the effect of film thickness on total solvent removal, three different film thicknesses were used, ranging from 0.01 to $0.05 \mathrm{~cm}$. The initial conditions of these three films were held constant for the purpose of comparison. Fig. 8 shows the results of the simulations. With increasing film thickness, we found that the initial rate of solvent removal decreased accordingly. Since the external conditions used in these simulations were the same, the results imply that the diffusion of solvents within the film has a profound effect in governing the rate of solvent removal.

To show the effect of the ratio of individual solvents on the overall rate of solvent removal, different methanol to water ratios were used while holding the polymer volume fraction constant. These methanol to water ratios ranged

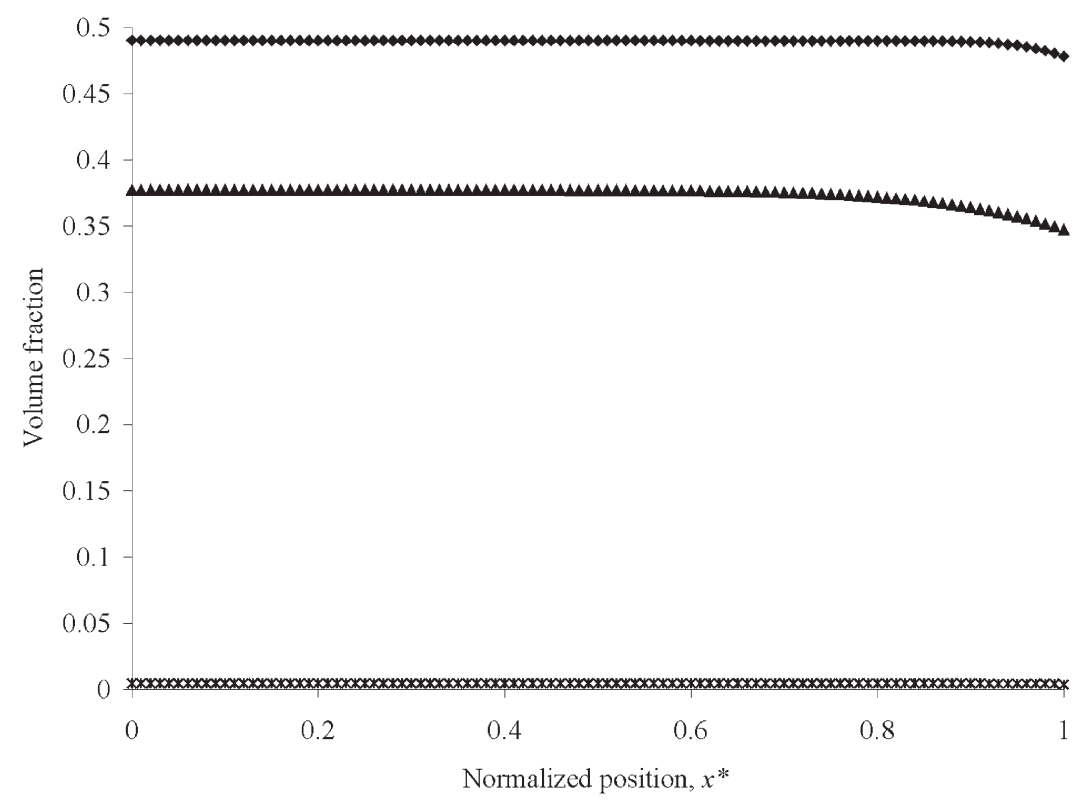

Fig. 4. Volume fraction profiles of water at different drying times. $(\diamond)$ Represent the drying behavior of water at 1 min drying while $(\boldsymbol{\Delta})$ and $(*)$ represent the water volume fraction at 10 and 100 min drying, respectively. 


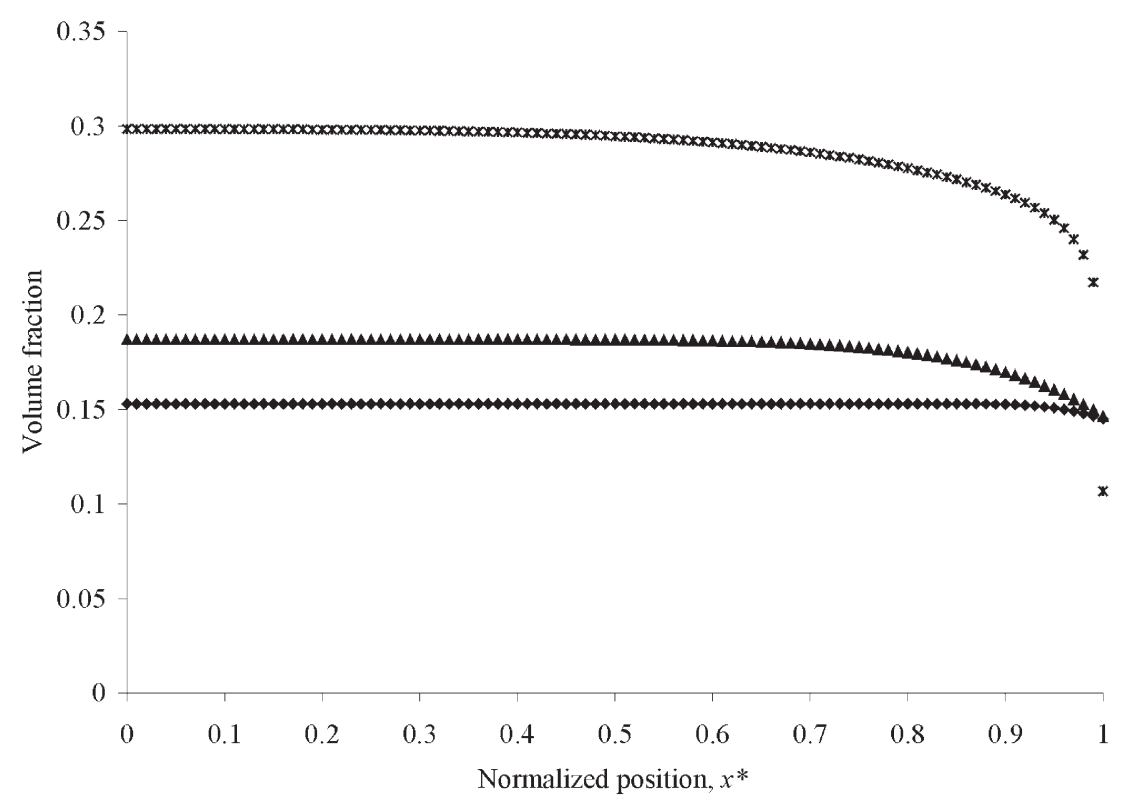

Fig. 5. Volume fraction profiles of methanol at different drying times. ( ) Represent the drying behavior of methanol at 1 min drying while $(\boldsymbol{\Delta})$ and ( $*$ ) represent the methanol volume fraction at 10 and 100 min drying, respectively.

from 1:2.25 to 1:5.5. Fig. 9 shows that initially, total residual solvents content does not depend on the methanol to water ratio since in this region the rate of drying is controlled by external conditions which were held constant for each ratio investigated. When external mass transfer resistance is no longer controlling the overall process, total residual solvents content decreased significantly with increasing water content. Increase in amount of faster diffusing component, water, helps to increase the diffusional rate of slower diffusing component, methanol, by increasing the free volume of the polymer. Thus, diffusional resistance is decreased, causing an overall decrease in total solvent content of the polymer film.
To study the effect of crystal growth on the overall solvent removal rate, three different crystallization kinetic constants were used $\left(5 \times 10^{-6}, 1 \times 10^{-5}\right.$ and $\left.5 \times 10^{-5} \mathrm{~s}^{-1}\right)$. Fig. 10 shows that the overall solvent removal rate in the first $30 \mathrm{~min}$ is virtually the same since external conditions were not changed. After $30 \mathrm{~min}$ of drying, in the case of higher crystal growth rate, the amount of solvent remaining in the system is higher than the case of lower crystal growth rate. The increase in crystallization rate constant causes an increase in the crystalline content of the polymer film, which hinders the diffusion and thus the removal of each solvent in the film. This result suggests that crystals within the polymer do play an important role on

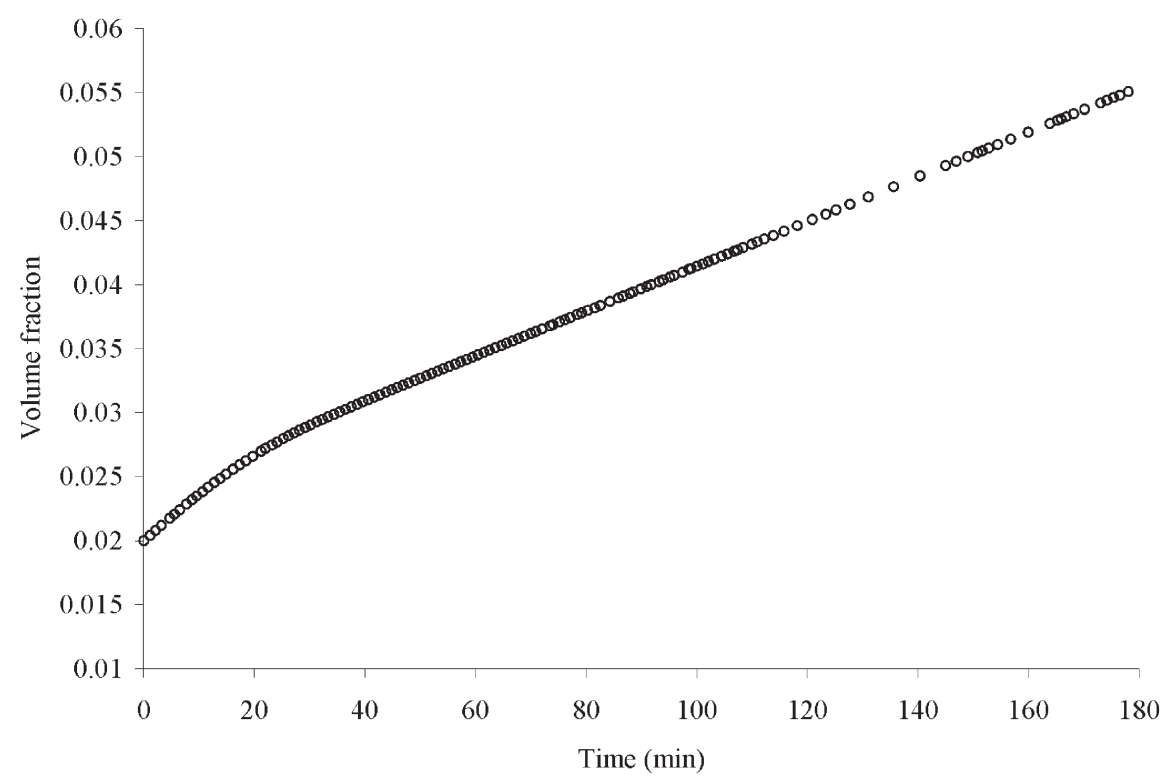

Fig. 6. Volume fraction of crystals $(\bigcirc)$ in polymer during drying. 


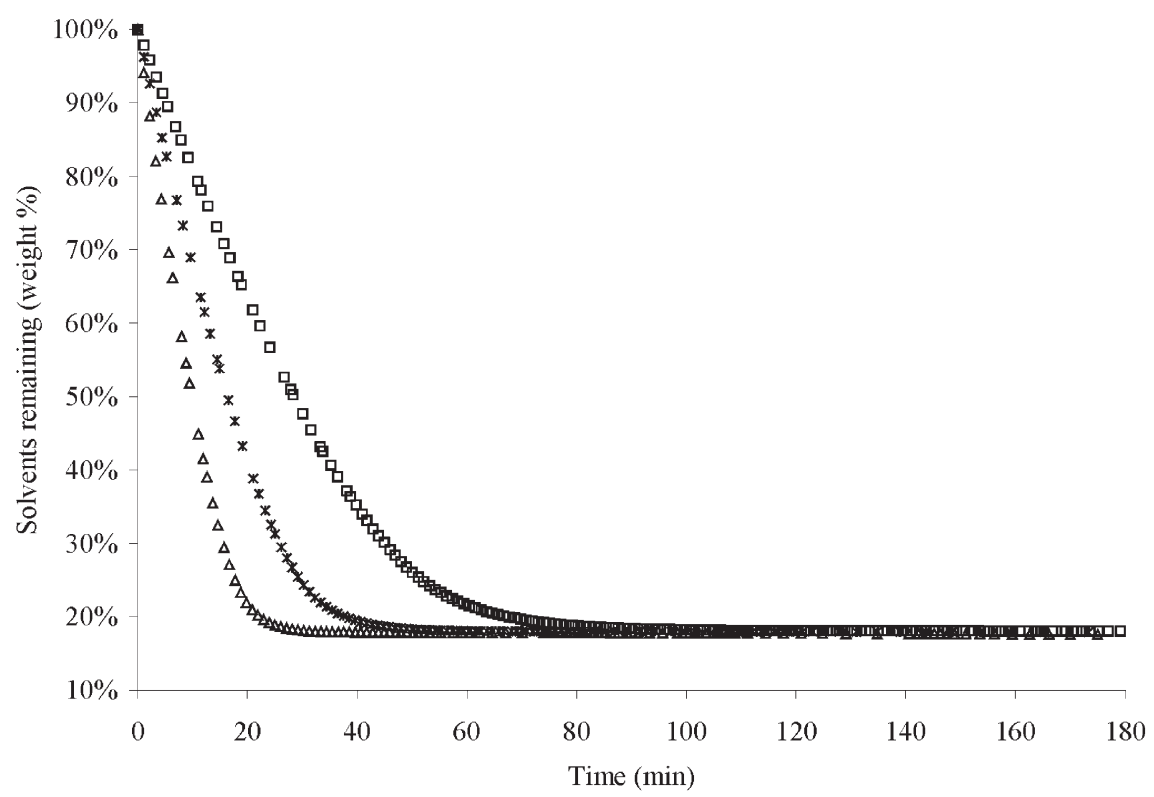

Fig. 7. Effect of temperature on residual solvent levels during drying. ( $\square),(*)$ and $(\triangle)$ represents the drying behavior at temperature 300,310 and $320 \mathrm{~K}$, respectively.

solvent removal kinetics, even though the magnitude of this effect is small in this case.

Based on our experimental data, we found that PVA films swell to a greater extent in water than in methanol. Therefore, the methanol content in our system was approximately $10 \%$ compared to $50 \%$ of water. Table 4 lists the conditions used in our experimental setup as well as corresponding simulation. Weight data obtained from experiments was translated to total weight percent of solvent remaining to allow direct comparison between experimental data and simulation results. For simulations, the external mass transfer conditions are used as fitting parameters. Fig. 11 shows that the both data are in good agreement. The predictions of the simulation results at the latter stage, where solvent removal is controlled by diffusion, are better compared to predictions at the earlier stage, where solvent removal is controlled by external conditions. This indicates that the diffusion model and the free volume parameters as well as the crystallization kinetics used are accurate and adequate to represent the drying behavior of PVA films.

This model represents the first step towards understanding the whole drying mechanism of multicomponent semicrystalline polymer. Nevertheless, further improvement of the

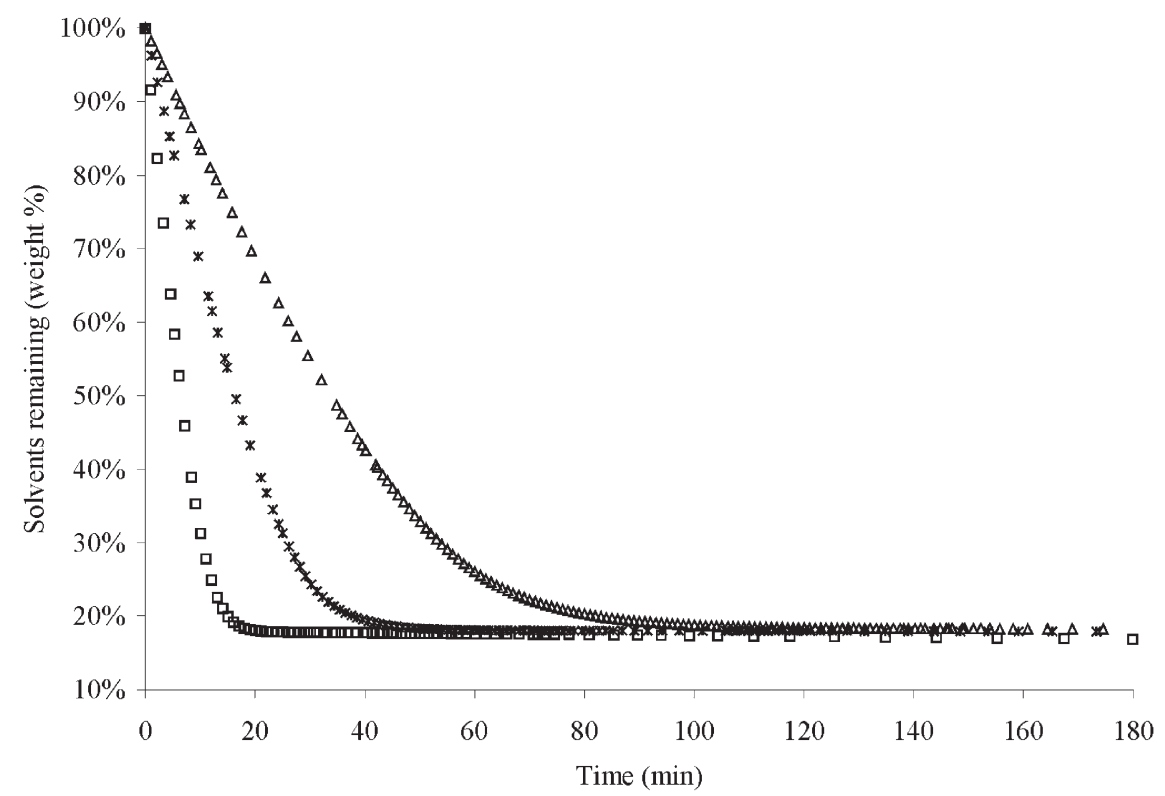

Fig. 8. Effect of film thickness on residual solvent levels during drying. ( $\square$ ), ( * ) and $(\triangle)$ represents the drying behavior at film thickness $0.1,0.25$ and $0.5 \mathrm{~mm}$, respectively. 


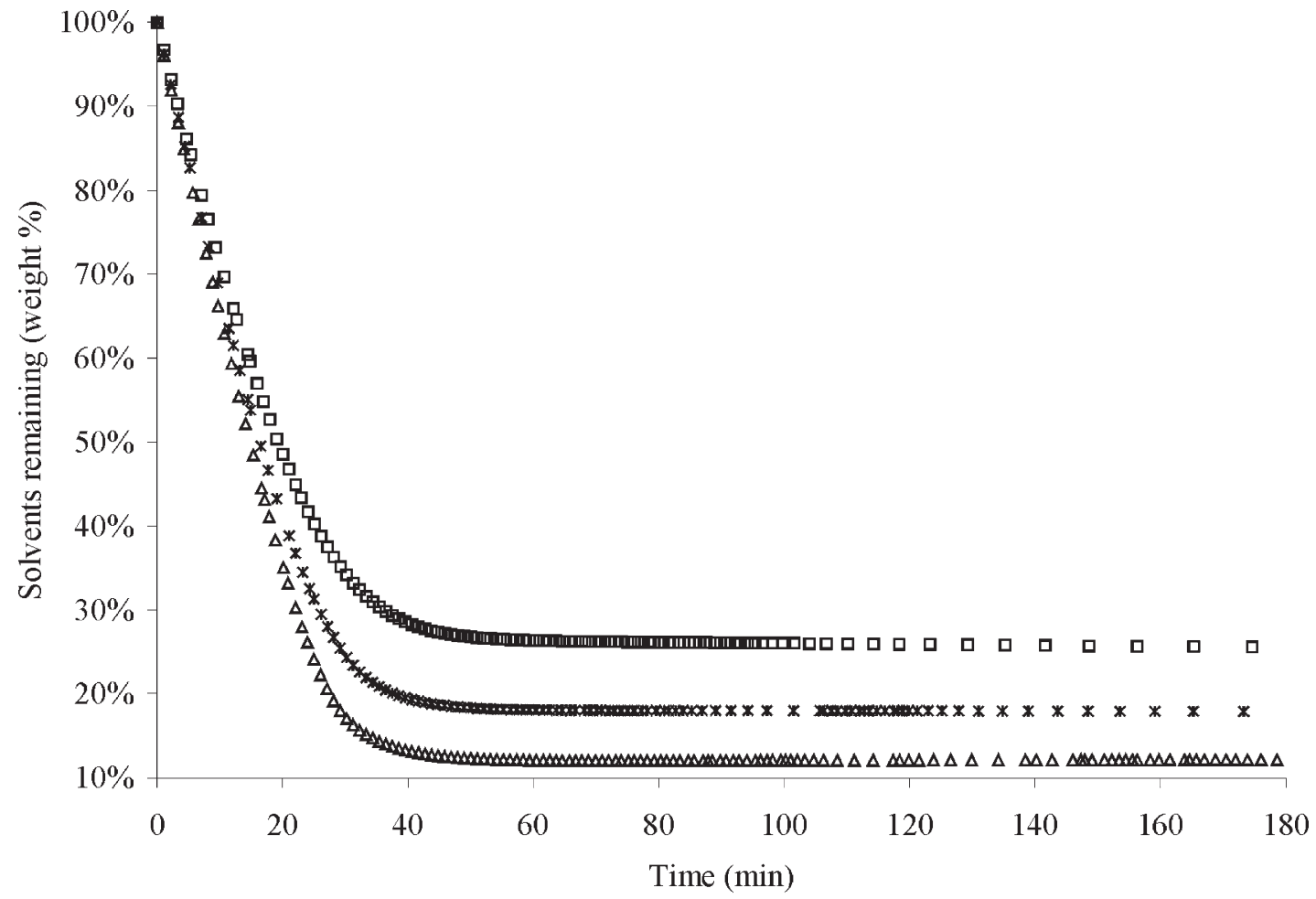

Fig. 9. Effect of different methanol to water ratios on residual solvent levels during drying. ( $\square$ ), ( * ) and $(\triangle)$ represents the drying behavior at methanol to water ratio $1: 2.25,1: 3.33$ and 1:5.5, respectively.

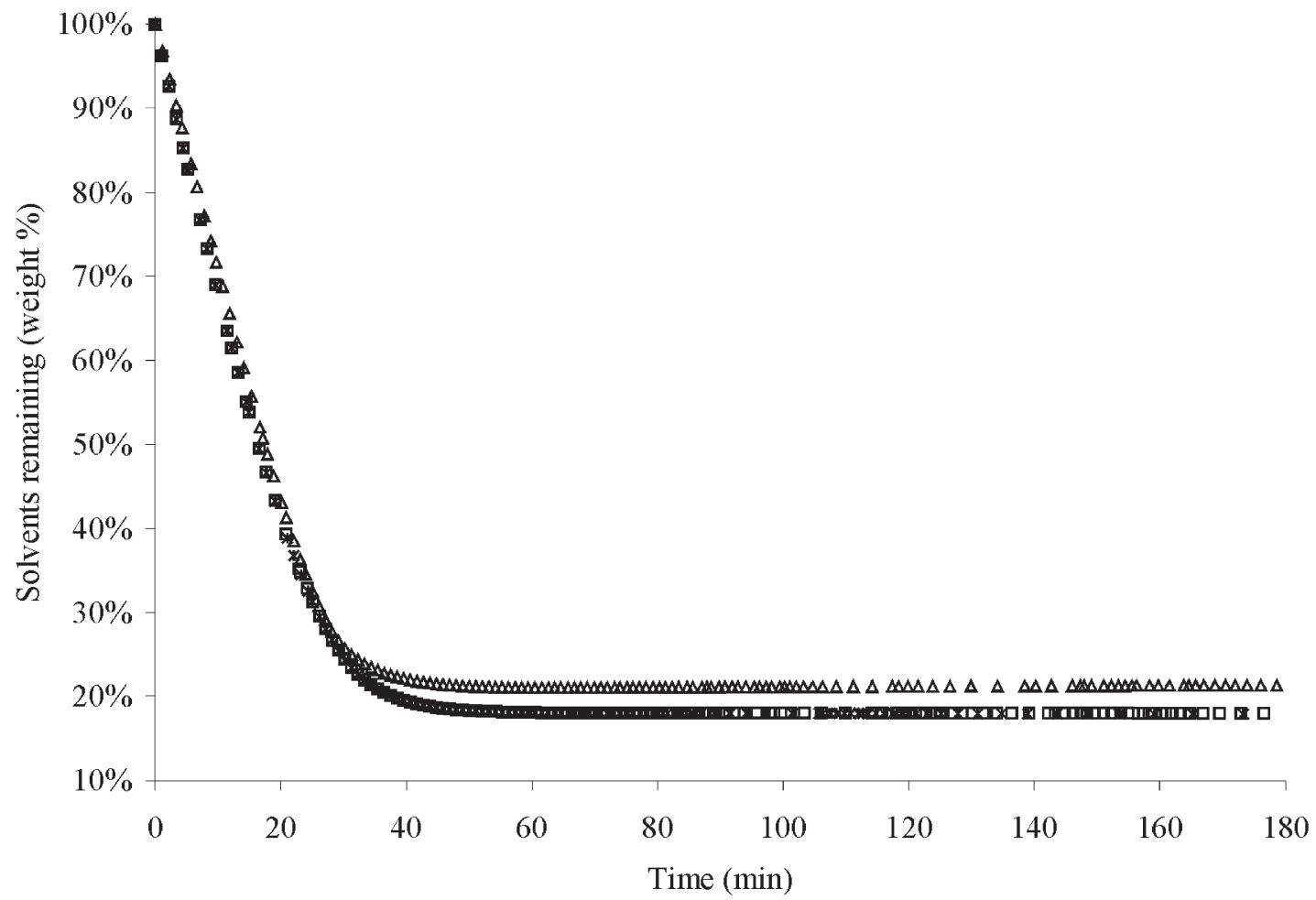

Fig. 10. Effect of crystallization kinetics on polymer crystal growth. $(\square),(*)$ and $(\triangle)$ represent the drying behavior at crystallization kinetic coefficients $\left(5 \times 10^{-6}, 1 \times 10^{-5}\right.$ and $\left.5 \times 10^{-5} \mathrm{~s}^{-1}\right)$, respectively. 
Table 4

Initial and boundary conditions for PVA/water/methanol system for experimental setup and simulation test $[39,40]$

\begin{tabular}{ll}
\hline Initial conditions & \\
Temperature, $T_{0}$ & $298(\mathrm{~K})$ \\
Film thickness, $L_{0}$ & $0.025(\mathrm{~cm})$ \\
Initial volume fraction of solvent $1, w_{10}$ & 0.6296 \\
Initial volume fraction of solvent 2, $w_{20}$ & 0.0512 \\
Initial volume fraction of crystalline polymer, $v_{0}$ & 0.02 \\
Initial volume fraction of amorphous polymer, $u_{0}$ & 0.2992 \\
Operating conditions & \\
Gas-polymer heat transfer coefficient, $h^{\mathrm{G}}$ & $0.10\left(\mathrm{~W} \mathrm{~cm}{ }^{-2} \mathrm{~K}^{-1}\right)$ \\
Gas-substrate heat transfer coefficient, $h^{\mathrm{g}}$ & $0.092\left(\mathrm{~W} \mathrm{~cm}{ }^{-2} \mathrm{~K}^{-1}\right)$ \\
Top-side air temperature, $T^{\mathrm{G}}$ & $298(\mathrm{~K})$ \\
Bottom-side air temperature, $T^{\mathrm{g}}$ & $298(\mathrm{~K})$ \\
Solvent 1 mass transfer coefficient, $k_{i}^{\mathrm{G}}$ & $1.7 \times 10^{-10}\left(\mathrm{~s} \mathrm{~cm}^{-1}\right)$ \\
Solvent 2 mass transfer coefficient, $k_{i}^{\mathrm{g}}$ & $2.3 \times 10^{-13}\left(\mathrm{~s} \mathrm{~cm}^{-1}\right)$ \\
Mole fraction of solvent 1 in gas & 0 \\
Mole fraction of solvent 2 in gas & 0 \\
\hline
\end{tabular}

model is needed to increase its accuracy as well as its ability to handle different drying conditions. Under certain drying conditions, a glassy skin can form at the polymer-air surface and change the diffusion at this region. This literal skinning phenomenon [37] effectively creates two different zones with two different diffusion coefficient and crystallization kinetics with an internal glassy-rubbery interface. This behavior can be addressed by dividing the current single zone diffusion into a two-zone diffusion system with moving internal boundary. Another possible improvement to this model is the development of a detailed crystallization kinetics expression. Currently, the model assumes a simple first order kinetic expression for crystallization. However, this might not be the case for some polymer and an expression that covers different kinetics mechanisms should be developed in the future.

\section{Conclusions}

We have developed a mathematical model to predict the multicomponent drying behavior of semicrystalline polymer films using multicomponent diffusion theory and solvent-induced crystallization kinetics as the backbone of the model. The model considers the effects of external conditions such as temperature, diffusion of each solvent in the polymer film, film shrinkage as well as the evaporation of each solvent from the surface. The model provides insights into how each solvent governs the overall solvent removal rate when diffusional resistances inside the polymer film are important. From our work, we find that higher temperatures, lower film thicknesses and higher water contents increase the rate of solvent removal. When compared to the experimental drying kinetics of PVA films, the model predictions are in good agreement with the experimental results. The model is not polymer specific, and can be applied to different polymer systems if the required parameters are available. Finally, we hope that this model can be used for optimizing the operation of existing ovens or designing new ovens required to remove the solvents from semicrystalline polymers.

\section{Acknowledgements}

The authors would like to thanks National Science Foundation for the financial support through Grant NSF CTS-0107168, and Dr John Zielinski of Air Products for providing the free volume parameters.

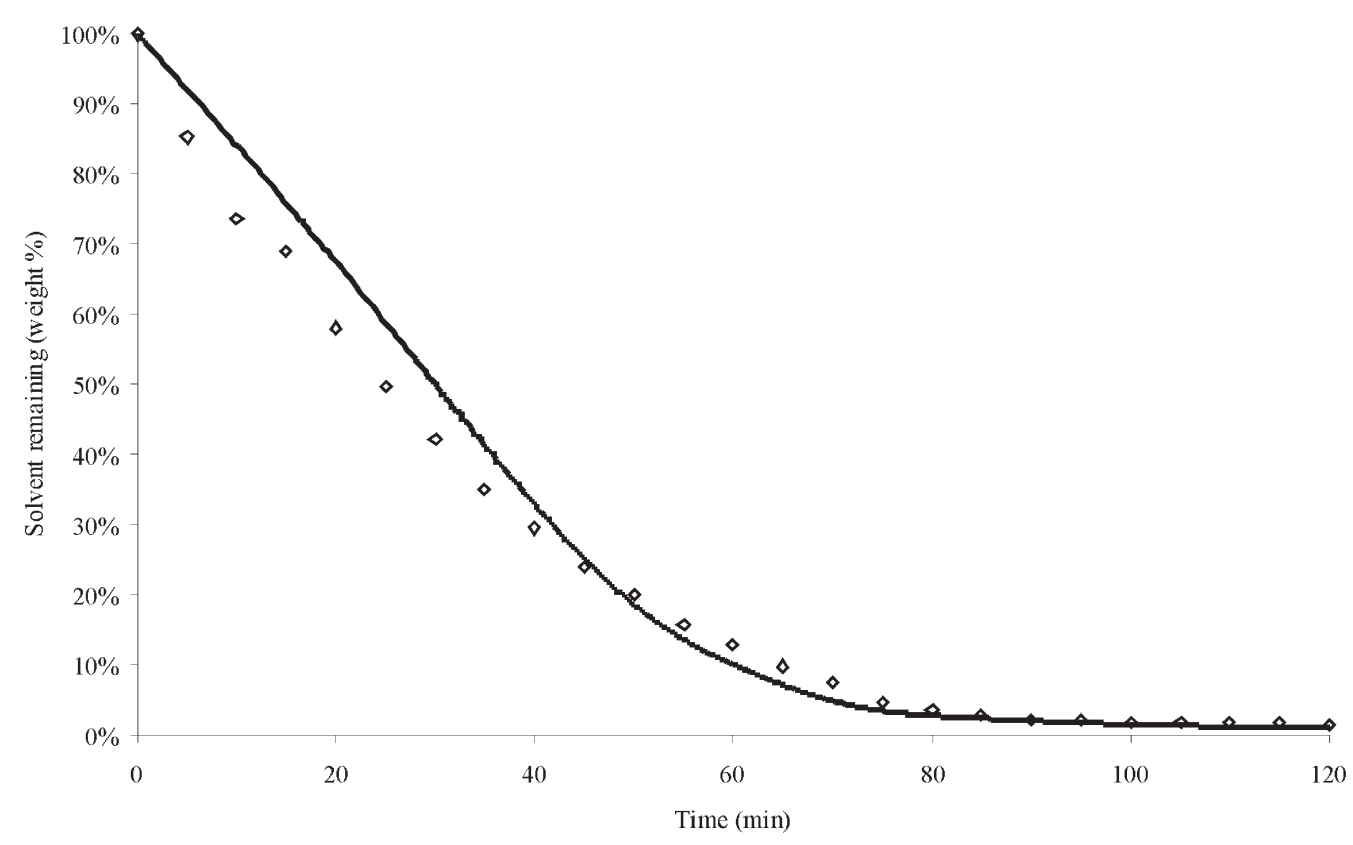

Fig. 11. Comparison between experimental results and simulation data on total solvent remaining during drying. $(\diamond)$ Represent the experimental data collected and (-) represents the simulation results correspond to the experimental conditions. 


\section{References}

[1] Alsoy S, Duda JL. AIChE J 1999;45:896.

[2] Alsoy S, Duda JL. Dry Technol 1998;16:15.

[3] Miltz J, Passay N, Mannheim CH. Packag Technol Sci 1992;5:49.

[4] Miltz J, Rosen-Doody V. J Food Process Pres 1984;8:151.

[5] Nir MM, Ram A, Miltz J. Polym Eng Sci 1996;36:862.

[6] Barr-Howell BD, Gordon EJ. Thermochim Acta 1991;180:147.

[7] Crapiste GH, Whitaker S, Rotstein E. Chem Eng Sci 1988;43:2919.

[8] Crapiste GH, Whitaker S, Rotstein E. Chem Eng Sci 1988;43:2929.

[9] Duda JL, Vrentas JS, Ju ST, Liu HT. AIChE J 1982;28:279.

[10] Errede LA. J Polym Sci, Part A: Polym Chem 1990;28:837.

[11] Errede LA. J Polym Sci, Part A: Polym Chem 1990;28:857.

[12] Errede LA, Aus EB, Duerst RW. J Polym Sci, Part A: Polym Chem 1992;30:1145.

[13] Errede LA, Henrich PJ, Schroepfer JN. J Appl Polym Sci 1994;54: 649.

[14] Errede LA, Henrich PJ, Tiers GVD. J Appl Polym Sci 1994;54:669.

[15] Errede LA, Kueker MJ, Tiers GVD, Van Bogart JWC. J Polym Sci, Part A: Polym Chem 1988;26:3375.

[16] Errede LA, Newmark RA. J Polym Sci, Part A: Polym Chem 1992;30: 1155.

[17] Errede LA, Tiers GVD, Trend JE, Wright BB. J Polym Sci, Part A: Polym Chem 1992;30:1129.

[18] Errede LA, Van Bogart JWC. J Polym Sci, Part A: Polym Chem 1989; 27:2015.

[19] Cairncross RA, Durning CJ. AIChE J 1996;42:2415.

[20] Price Jr PE, Cairncross RA. J Appl Polym Sci 2000;78:149.

[21] Price Jr PE, Cairncross RA. Dry Technol 1999;17:1303.
[22] Romdhane IH, Price Jr PE, Miller CA, Benson PT, Wang S. Ind Eng Chem Res 2001;40:3065.

[23] Ngui MO, Mallapragada SK. J Appl Polym Sci 1999;72:1913.

[24] Ngui MO, Mallapragada SK. J Polym Sci, Part B: Polym Phys 1998; $36: 2771$.

[25] Ngui MO, Mallapragada SK. Polymer 1999;40:5393.

[26] Vrentas JS, Duda JL. J Polym Sci, Polym Phys Ed 1977;15:403.

[27] Vrentas JS, Duda JL. J Polym Sci, Polym Phys Ed 1977;15:417.

[28] Vrentas JS, Duda JL, Ling HC. J Polym Sci, Polym Phys Ed 1985;23: 275.

[29] Vrentas JS, Duda JL, Ling HC, Hou AC. J Polym Sci, Polym Phys Ed 1985;23:289.

[30] Zielinski JM, Duda JL. AIChE J 1992;38:405.

[31] Harland RS, Peppas NA. Colliod Polym Sci 1989;267:218.

[32] Favre E, Nguyen QT, Clement R, Neel J. Eur Polym J 1996;32:303.

[33] Lauritzen Jr JI, Hoffman JD. J Res Natl Bur Std 1960;64A:73.

[34] Schultz JM. Polymer materials science. Englewood Cliffs, NJ: Prentice Hall; 1974.

[35] Crank J. Free and moving boundary problems. Oxford: Clarendon Press; 1984.

[36] Peppas NA, Merrill EW. J Polym Sci, Polym Chem Ed 1976;14:441.

[37] Edwards DA. Macromol Theor Simul 1999;8:10.

[38] Zielinski JM. Personal communication, Air Products Inc, Allentown, PA; 2003.

[39] Brandrup J, Immergut EH. Polymer handbook, 3rd ed. New York: Wiley; 1989.

[40] Perry RH, Green DW, Maloney JO. Perry's chemical engineer's handbook, 7th ed. New York: McGraw-Hill; 1997. 